\title{
The effects of sensory and activity deprivation on choice of an incentive'
}

FAWN D. HEWITT, THE UNIVERSITY OF DURHAM, ENGLAND WNFRED F. HILL, NORTHWESTERN UNIVERSITY ${ }^{2}$

Twelve female albino rats, subjected for 24-hr. periods to (1) sensory stimulation coupled with activity deprivation; (2) unrestricted activity accompanied by sensory deprivation; or (3) a normal laboratory group condition, were given a choice between incentives of sensory experience and a Wahmann activity wheel immediately following each period of confinement. While there was no significant effect of conditions upon initial choice, over 42 days with one 8-min. trial daily, Ss spent more time at the sensory incentive and less time at the activity incentive following condition 2 than following the other 2 conditions.

The place of activity in the ordering of psychological phenomena has long proved a problem to researchers. One recent view has been that of activity understood as autonomous drive (Hill, 1956, 1958). Hill (1961) predicted that rats when deprived of activity would show increased preference for the arm of a $\mathrm{T}$-maze allowing them to satiate their drive. While Ss preferred the activity incentive over the sensory incentive, there was no significant difference among conditions in choice of activity. However, Ss displayed greater activity upon reaching the incentive following confinement than under control conditions. The present study attempted to replicate his work with further refinement of sensory deprivation and incentive.

Subjects and Apparatus

Ss were 12 female albino rats of the SpragueDawley strain, about 60 days old at the beginning of the study.

Choice behavior was measured individually in a $28 \times 18 \times 12$ in. box, painted a flat gray. A separate $5 \times 12 \times 4$ in. Plexiglas start box, with a sliding door at one end, was used at the entrance to the apparatus' choice point. At the choice point, $S$ was exposed to the incentives. Directly to the right of the entrance was a hardware cloth tunnel, leading on a slight upward incline to the entrance of the activity incentive, a Wahmann activity wheel. Directly ahead of the choice point was the sensory incentive, a portion of the apparatus $12 \times 8 \times 6$ in. and L-shaped, in which were scattered and hung paper clips, colored wooden pieces, paper wads, etc. These were also present in a 6 in. deep portion of the apparatus, visible to $S$ in the sensory incentive, but non-accessible due to a hardware cloth and glass barrier. A $100-\mathrm{W}$ bulb was located approximately $5 \mathrm{ft}$. above the maze, and two electric timers enabled $E$ to record time at each incentive.

Three living conditions were provided:

(1) The sensory condition, in which Ss were housed in $9 \times 6 \quad 6 \quad x \quad 3$ in. hardware cloth, slant-roofed cages, designed to restrict activity. Two of these cages formed one larger unit, so that only a common hardware cloth partition separated the Ss. Objects much the same as those in the sensory incentive were scattered and hung throughout the cages.

(2) The activity condition, consisting of Wahmann activity wheels (14 in. in diameter, 4-1/2 in. wide) and their living units ( $10 \times 6 \times 5$ in.) attached with the door open, so access to the wheel was always possible. No S could see any other $S$.

(3) The group condition, in which all four Ss in that condition at any given time were housed in a $30 \times 36$ $x 8$ in. hardware cloth cage. A small munning wheel and teeter totter were in the cage at all times.

The sensory and group conditions were in a constantly lighted room with other animals, and the activity condition was in a completely darkened room. The conditions, then, were (1) activity deprivation with above normal opportunity for sensory stimulation; (2) sensory deprivation with above normal opportunity for activity; and (3) a group condition, allowing relatively normal activity and sensory stimulation.

\section{Design}

Each S lived $24 \mathrm{hr}$. at a time in each of the three conditions and was tested at the same time each day at the end of the 24-hr. period in the given condition. Ss were changed to the subsequent condition following the test period.

Two Ss received the three conditions in each of the six possible sequences. Each $\mathrm{S}$ remained in this same sequence for the duration of the study. Three successive tests, one under each condition, constituted one cycle; all Ss went through 14 cycles.

\section{Procedure}

Each $\mathrm{S}$ received $6 \mathrm{~min}$. of experience in the choice apparatus on each of three consecutive days prior to the beginning of the experimental period. On the first day, unrestricted exploration was allowed. On the second and third days, half of the time was spent at each incentive, with the first incentive for each day determined randomly; one incentive was blocked, forcing $S$ to explore the other. During this pretraining and prior to it, all Ss were housed in normal laboratory conditions. Following the last day of pretraining, each $S$ was placed into one of the three living conditions, determined by the sequence to which that $S$ had been assigned.

Testing was conducted each day for 42 consecutive days, with each $S$ tested 14 times under the effects of 
Table 1.

Time in minutes at the two incentives (Each entry is the mean of 12 Ss over 14 cycles)

\begin{tabular}{lcccc}
$\begin{array}{l}\text { Previous } \\
\text { Living }\end{array}$ & \multicolumn{2}{l}{ Two-minute period } & \multicolumn{2}{l}{ Eight-minute period } \\
Condition & $\begin{array}{l}\text { Sensory } \\
\text { Incentive }\end{array}$ & $\begin{array}{c}\text { Activity } \\
\text { Incentive }\end{array}$ & $\begin{array}{l}\text { Sensory } \\
\text { Incentive }\end{array}$ & $\begin{array}{c}\text { Activity } \\
\text { Incentive }\end{array}$ \\
\hline Sensory & .445 & 1.298 & 1.991 & 5.129 \\
Activity & .886 & .809 & 3.666 & 3.364 \\
Group & .423 & 1.329 & 1.908 & 5.304 \\
\hline
\end{tabular}

Note. The means given above are based on measures which are not independent, but which do not sum to 2 and 8 min., respectively. due to the time spent at the choice point.

each of the three living conditions. There was one 8-min. trial daily for each S, during which S was permitted to explore both incentives. The time spent at each incentive in the initial $2 \mathrm{~min}$. and in the total period was recorded, as was the initial choice of incentive.

\section{Results and Discussion}

The results of the analysis of variance conducted on the initial choice data concur with those found by Hill (1961): there was no significant effect of living conditions on incentive choice. While Ss displayed greater wheel choice under the activity deprived condition than under the other two conditions, this was not significant.

Mean times spent at each incentive are shown in Table 1. Four analyses of variance were conducted on these data: time at (a) the sensory incentive in the first $2 \mathrm{~min}$.; (b) the activity incentive in the first 2 min.; (c) the sensory incentive in the full $8 \mathrm{~min}$.; and (d) the activity incentive in the full $8 \mathrm{~min}$. All four analyses showed the effect of living conditions to be significant at the .001 level $(F=138.14,98.68,304.63$, and 272.07, respectively, $\mathrm{df}=2 / 12$ ). The significance in all cases was due to the difference between the activity condition and the other two conditions, which tended to cluster together. The sensory condition actually gave slightly more time at the sensory incentive and less time at the activity incentive than did the group condition, contrary to prediction.

It is also of interest that the activity incentive was greatly preferred by all Ss, initially at least. However, over trials, the time at the activity incentive decreased for all groups, accompanied by a gradual increase in the time spent at the sensory incentive. This overall shift is reflected in the $8-\mathrm{min}$. period data by a significant $(p<.01)$ cycles effect $(F=3.75$ for the sensory incentive data and 2.48 for the activity incentive data, $\mathrm{df}=13 / 78)$. Corresponding $F$ values for the initial 2-min. period were 2.11 and $2.47, p<$ .05 for the former and $p<.01$ for the latter.

The findings raise the question of whether $\mathrm{Ss}$ in reality discriminated between two drives, or between levels (or presence or absence) of one drive. Two such single-drive interpretations are plausible: (1) that a sensory drive is the major factor, with only the activity group being sensory deprived; or (2) that an activity drive is the major factor, with only the activity group being activity satiated. The latter interpretation would imply that the opportunity for activity in a large, flat cage is not sufficient to satiate activity drive as measured by wheel-running, a conclusion consistent with Hill (1961), but in conflict with Hill (1956).

It is suggested that activity drive might best be measured in the future by more than one instrument, e.g., both a wheel and a field maze, so that any existing components of activity might be ascertained.

\section{References}

Hill, W. F. Activity as an autonomous drive. J. comp. physiol Psychol., 1956, 49, 15-19.

Hill, W. F. The effect of varying periods of confinement on activity in tilt cages. J. comp. physiol. Psychol., 1958, 51, 570-574. Hill, W. F. Effects of activity deprivation on choice of an activity incentive. J. comp. physiol. Psychol., 1961, 54, 78-82.

\section{Notes}

1. These findings are based on a thesis of the same title submitted to Northwestern University by the first author in partial fulfillment of the requirements of the Master of Arts degree.

2. Currently at the Center for Advanced Study in the Behavioral Sciences, Stanford, California. 